\section{Sea Rescue in the World}

Yao Zhong Chen

Faculty of Naval Medicine Second Military Medical University, Shanghai, PEOPLES' REPUBLIC OF CHINA

There has been increasing emphasis in the world on seafaring safety, sea rescue, and self-rescue of vessels. At present, sea rescue displays the following characteristics: 1 ) the responsibilities of international rescue organizations have increased; 2) rescue organizations of countries have been perfected further; 3 ) rescue appliances have become more advanced; and 4) rescue methods have improved further.

On the average, 99 ships sink each year. The data of Chinese Ministry of Communications displays that the proportion of destroyed evidence merchant ships is $0.412 \%$ and the proportion of heavy $3.92 \%$ every year.

The problems associated with sea include: 1) the sea environment itself poses difficulties for human survival; 2) the command and organization of sea rescue is very complex; 3) rescue is highly affected by atmospheric conditions; 4) emergency medical evacuation is very difficult; and 5) advanced appliances are required.

This discussion introduces the sea rescue organizations of America, Japan, Russia, England, France, Canada, Australia, and China, and their history, position, responsibility and function are described in detail. It introduces the function of "IMO", "LMSO", the components of sea rescue system, the current situation of doing wireless urgent medical service on the sea, and on-site command and control of sea rescue.

Keywords: accidents; international; organization; rescue; safety; sea
Activities of Kobe University Medical Team for

Taiwan Earthquake, and Comparison between Initial Responses following the Kobe and Taiwan Earthquakes

Shinicbi Nakayama, MD, PhD; Hitoshi Matsuda; Dr. Naoki Okada; Dr. Yasubiro Toyoda; Dr. Jai Miyazaki; Noboru Ishii, $M D, P b D$

Department of Disaster and Emergency Medicine, Kobe University School of Medicine, Kobe, JAPAN

Kobe University dispatched its medical team, KUMT, to Taiwan to provide medical assistance following the Taiwan Earthquake in 1999. In this paper, the initial responses to this disaster will be compared with those following the Kobe Earthquake in 1995. The activities of KUMT will be described..

KUMT, which consisted of 4 surgeons, 2 nurses, and 1 pharmacist, left for Taiwan on 22 September, the next day after the earthquake. KUMT was welcomed by the Taichung City Health Bureau (TCHB) as its counterpart. Their joint team established a temporary clinic at Neichung village in Nantou Hsien on 23 September. Critical trauma victims had been transported to hospitals in nearby cities before their arrival. In four days, 298 victims, which included 102 trauma patients and 196 medical patients, were treated at the clinic. The team treated 40 victims at other villages with domestic medical teams mobilized from Taichung, Taipei, and Kaohsiung. KUMT also tried to transmit their lessons from Kobe Earthquake to medical professionals and evacuees in Taichung to help with mitigation.

KUMT has achieved its initial goals by its prompt dispatch and collaboration with its counterpart. Domestic and foreign medical relief by GO and NGO teams were more promptly and more efficiently activated in acute phase in Taiwan Earthquake than in Kobe Earthquake.

Keywords: clinics; earthquake; international assistance; Kobe;

KUMT; medical relief; patients, description of; teams; Taiwan

E-mail: shin@med.kobe-u.ac.jp 